\title{
The Retardation of Enamel Dissolution Rates by Adsorbed Long-Chain Ammonium Chlorides
}

\author{
T. J. ROSEMAN*, W. I. HIGUCHI, B. HODES, and J. J. HEFFERREN \\ College of Pharmacy, University of Michigan, Ann Arbor, Michigan 48104, and the Ameri- \\ can Dental Association, Chicago, Illinois 60611
}

\begin{abstract}
Dissolution rate studies were conducted with hydroxyapatite and enamel in the presence of adsorbed surfactants. In general, the ability of the surfactant to retard the dissolution rate was directly related to its ability to adsorb onto apatite. Cetylpyridinium chloride adsorbed poorly onto apatite, and its influence on the dissolution rate was marginal. The long-chain protonated amines were much more effective as rate retarding agents, sometimes of the order of 1,000-, to 10,000-fold. These compounds were also found to adsorb much more strongly. A systematic dependence of the dissolution rate on chain length was found for these amines.
\end{abstract}

In vitro studies ${ }^{1-3}$ have demonstrated that certain organic compounds retard the dissolution of enamel. Although other investigators $^{4-9}$ have suggested a relationship between the phenomenon of adsorption at the enamel-liquid interface and the reduction in enamel solubility, little definitive information has been presented to correlate adsorption isotherms and dissolution rates. Equilibrium considerations for adsorption concomitant with dissolution experiments have been omitted, and conclusions have been based on one short-time interval. Therefore, previous studies of the influence of organic surface adsorbing agents on enamel solubility or antisolubility have not differentiated

This investigation was based on a thesis submitted to the graduate school, College of Pharmacy, University of Michigan, in partial fulfilment of the requirements for the $\mathrm{PhD}$ degree.

This investigation was presented at the 46th general meeting of the IADR, San Francisco, March 21, 1968.

This investigation was supported in part by USPHS grants 1-FE-DE-23, 781, and DE-01830 from the National Institute of Dental Research, National Institutes of Health, Bethesda, Md.

Received for publication May 16, 1968.

* Present address: The Upjohn Company, Kalamazoo, Mich. between rates of dissolution and solubility of enamel.

This report describes the first step of a quantitative study of the environmental conditions which can alter the adsorption process and their relation to the reduction in enamel dissolution rates. These experiments were first conducted with apatite, which is known to be the main constituent of the inorganic part of enamel. The results of this phase of the research were then correlated with enamel dissolution rate experiments.

\section{Materials and Methods}

The primary amine hydrochloride surfactants, $n$-decyl-, $n$-dodecyl-, $n$-tetradecyl-, and $n$-hexadecyl ammonium chloride, were prepared by bubbling anhydrous hydrogen chloride gas through a prefiltered solution (ca $4 \%$ ) of free aminet in benzene. The hydrochloride was recrystallized three times from benzene. Practical grade cetylpyridinium chloride $\ddagger$ was recrystallized once from acetone. A commercial synthetic hydroxyapatite§ (Victor apatite) was dried overnight at $110 \mathrm{C}$ and was used for the adsorption study. The synthetic apatite which was used for the dissolution experiments was prepared according to the method of the Tennessee Valley Authority\| and will be designated as TVA apatite. The chemical composition and specific surface areas are given in Table 1. The low surface area of the TVA apatite sample necessitated the use of two differently prepared hydroxyapatite samples during this investigation. Sur-

\footnotetext{
$\dagger$ Aldrich Chemical Co., Milwaukee, Wis.

\$ Eastman Organic Chemicals, Rochester, NY.

\$ Stauffer Chemical Co., Victor Division, New York,

\| Division of Chemical Development, Wilson Dam,
} NY. 
TABLE 1

Composition and Surface Areas of Hydroxyapatite SaMPLes

\begin{tabular}{lcc}
\hline & TVA & Victor \\
\hline \% Phosphate theoretical & 56.7 & 56.7 \\
\% Phosphate experimental & 56.9 & 54.4 \\
\% Calcium theoretical & 39.9 & 39.9 \\
\% Calcium experimental & 38.4 & 35.4 \\
$\mathrm{Ca} / \mathrm{PO}_{4}$ Molar ratio theoretical & 1.67 & 1.67 \\
$\mathrm{Ca} / \mathrm{PO}_{4}$ Molar ratio & & \\
experimental & $1.64-1.68$ & 1.54 \\
Specific surface area $\left(\mathrm{M}^{2} / \mathrm{gm}\right)$ & 1.17 & 66.1 \\
\hline
\end{tabular}

face areas were determined by the B.E.T. gas adsorption technic.*

Adsorption experiments were carried out by adding $10 \mathrm{ml}$ of known adsorbate concentrations to known weights of Victor apatite $(100 \mathrm{mg}$ or $500 \mathrm{mg}$ ) into pyrex culture tubes. The tubes were rotated at $40 \mathrm{rpm}$ in a constant-temperature bath by means of an end-over-end tumbling apparatus. At adsorption equilibrium, samples were withdrawn through 20 gauge 6 -inch needles attached to $10 \mathrm{ml}$ syringes and filtered through Swinny hypodermic adapters which contained 0.22 micrometer $(\mu \mathrm{m})$ filters. $t$ The predetermined adsorption equilibrium time was approximately 30 minutes, but the tubes were allowed to rotate overnight. At high adsorbate concentrations, the tubes were centrifuged before the samples were withdrawn. The clear supernatant solution was analyzed for the equilibrium surfactant concentration. The dodecylammonium chloride concentration was determined according to the antagonistic titration method of Ino, Kondo, Meguro, and Yoda, ${ }^{10}$ using sodium lauryl sulfate as the titrant and rhodamine $6 \mathrm{G}$ as the adsorption indicator. The precision of the assay was $\pm 2 \%$. An ultraviolet analysis was used for cetylpyridinium chloride (CPC) at a wavelength of $259 \mathrm{~m} \mu$. The number of millimoles of adsorbed surfactant was calculated by multiplying the concentration change by the volume.

Dissolution experiments with TVA hydroxyapatite were performed on previously equilibrated (18 hour) adsorbed samples. A $100 \mathrm{mg} / 10 \mathrm{ml}$ slurry containing apatite and surfactant was quantitatively transferred to a $250 \mathrm{ml}$ volumetric flask fastened on a wrist-action shaker. $\ddagger$ The temperature was

* Perkin-Elmer Shell Sorptometer, Perkin-Elmer Corp., Norwalk, Conn.

$\uparrow$ Millipore Filter Corp., Bedford, Mass.

Burrell Corp., Pittsburgh, Pa. maintained at $30 \mathrm{C}$. Two hundred milliliters of a buffer or buffer-surfactant solution (previously equilibrated at $30 \mathrm{C}$ ) were added and the shaker and a timer were simultaneously started. Surfactant was incorporated into the buffer to maintain the equilibrium adsorption concentration. Samples were withdrawn at various time intervals with 7 -inch needles into $10 \mathrm{ml}$ syringes and were filtered through $0.22 \mu \mathrm{m}$ filters contained in Swinny hypodermic adapters. The total number of milligrams of hydroxyapatite dissolved at any time was calculated from the amount of phosphate present. Phosphate ion in solution was determined according to the method of Gee, Domingues, and Deitz. ${ }^{11}$ In order to verify that the apatite was dissolving stoichiometrically, calcium ion concentrations were selectively determined by means of an atomic absorption spectrophotometer. $\S$ Since the acid slurry contained dissolved apatite, the amount present was calculated from a duplicate sample which was filtered. This amount was subtracted from the total amount going into solution. Therefore, graphical representations gave the net amount of hydroxyapatite dissolved as a function of time.

The enamel dissolution studies were performed on six selected teeth embedded in a wax matrix mount. The mount, in the shape of a doughnut, was secured to the bottom of a $180 \mathrm{ml}$ jacketed beaker. Temperature was maintained constant at $30 \mathrm{C}$. One hundred milliliters of a buffer or buffersurfactant solution were added, the solution was stirred at 1,800 rpm, and samples were withdrawn at the various time intervals. As was the case with the hydroxyapatite powder, the surfactant was preadsorbed (for 30 minutes in this instance) under the same experimental conditions, ie, $\mathrm{pH}$, buffer strength, and surfactant concentration, as those for dissolution. After the adsorption time, the buffer-surfactant solution was decanted, and fresh buffer-surfactant solution was added. The dissolution of the enamel was then followed. After each experiment, the mount was washed with fresh buffer to remove any adsorbed surfactant. Figure 1 shows the effect, and therefore demonstrates the need for the preadsorption of the adsorbing agents.

\footnotetext{
\& Perkin Elmer, Model 303, Norwalk, Conn.
} 




$\mathrm{A}, \mathrm{O}$, Control; $\mathrm{B}, \square, 0.3 \mathrm{mMTAC}$ with no preadsorption; $\mathrm{C}, \triangle, 0.3 \mathrm{mM} \mathrm{TAC}$ after preadsorption.

FIG 1.-Effect of preadsorption of tetradecylammonium chloride on enamel dissolution at pH $4.5(0.05 M$ acetate buffer $)$ at $30 \mathrm{C.} *$

* All determinations done at $30 \mathrm{C}$.

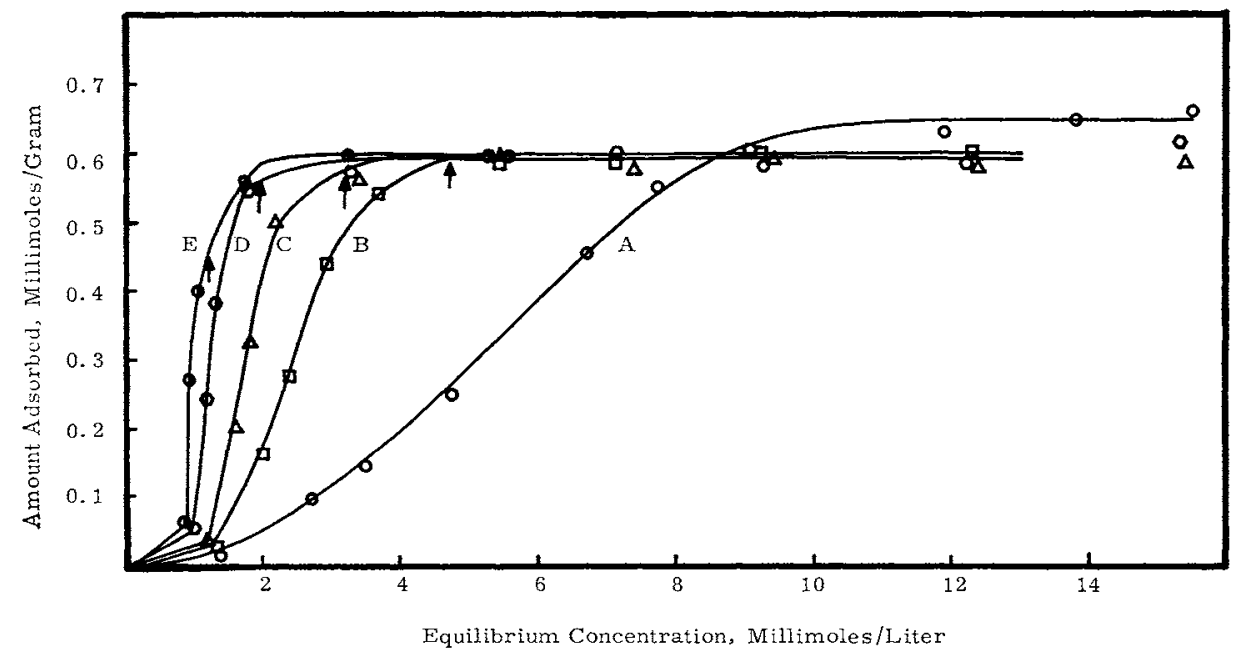



$E, \bullet, 0.3 M(\mu=0.3)$. Arrows signify approximate critical micelle concentrations.

FIG 2.-Adsorption isotherms of dodecylammonium chloride onto Victor apatite in sodium chloride solutions showing the influence of ionic strength. Arrows signify approximate critical micelle concentrations. 




FIG 3.-Adsorption isotherms of dodecylammonium chloride onto Victor apatite at $\mathrm{pH} 4.5$ ( $0.05 M$ acetate buffer) in sodium chloride solutions showing the influence of ionic strength.

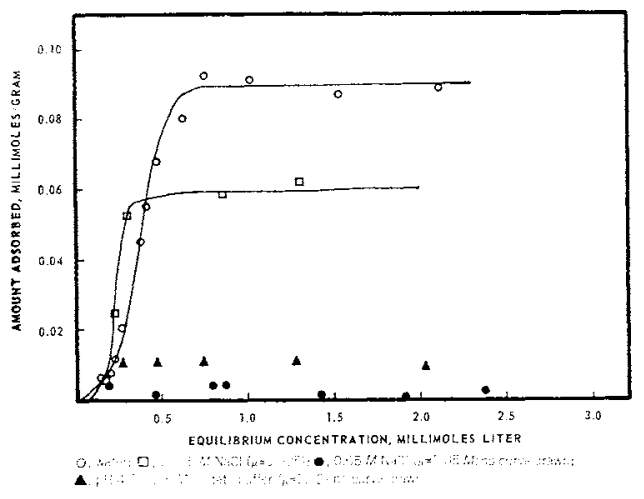

FIg 4.-Adsorption isotherms of cetylpyridinium chloride onto Victor hydroxyapatite in different media.

An interfacial tensiometer* was used to determine the approximate critical micelle concentrations of the surfactants.

\section{Results}

The results of adsorption studies with the surfactant dodecylammonium chloride (DAC) and CPC are presented in Figures $2-4$. The $S$-shaped curves are in contrast to Langmuirian type of adsorption, where the curves are initially linear with no inflection. Experiments performed in $\mathrm{pH} 4.5$ and 6.0 , $0.05 M$ acetate buffer showed differences

* Cenco-du Noüy, Central Scientific Co., Chicago, Ill. in the adsorption behavior of the surfactants investigated. Further studies, considering the ionic strengths of the solutions, showed that these differences could be explained by an ionic strength effect.

Figures 2 and 3 illustrate the effect of increasing ionic strength, $\mu$, (by the addition of sodium chloride) on the adsorption of DAC onto Victor apatite in water and $\mathrm{pH}$ $4.5(0.05 M)$ acetate buffer respectively. A decided effect was observed showing a distinct displacement of the curves to lower equilibrium surfactant concentrations. The maximum amount adsorbed remained the same. The adsorption of CPC (Fig 4), on the other hand, showed an apparent reversal of this ionic strength dependency. The curves indicate no displacement but showed a decrease in the maximum amount adsorbed. Sodium chloride $(0.05 M)$ essentially prevented any significant adsorption. Figure 4 also shows that no measurable adsorption of CPC occurred in $\mathrm{pH} 4.5,0.05$ $M$ acetate buffer.

Retardations of the dissolution rates of the TVA hydroxyapatite sample and enamel were observed with all members of the longchain homologous series of the protonated, primary amines studied, decyl-, dodecyl-, tetradecyl-, and hexadecylammonium chlorides. CPC, although another cationic surface active agent, caused no significant re- 


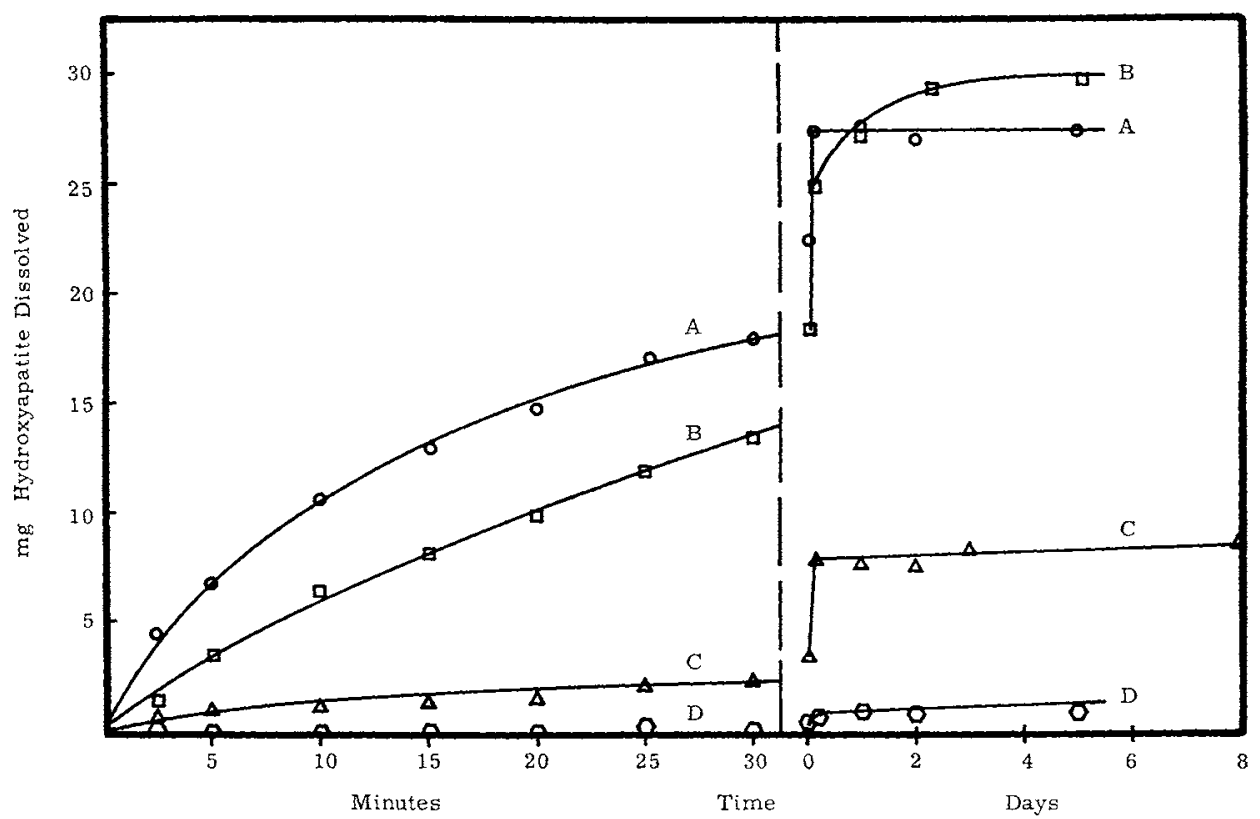

$A, O$, Controi; $8, \mathrm{D}, 3.0 \mathrm{mM} ; \mathrm{C}, \triangle, 4.0 \mathrm{mM} ; \mathrm{D}, 0,5.0 \mathrm{mM}$.

Fig 5, 5a-Dissolution profiles of preadsorbed TVA apatite in various dodecylammonium chloride solutions in $\mathrm{pH} 4.5,0.05 \mathrm{M}$ acetate buffer.

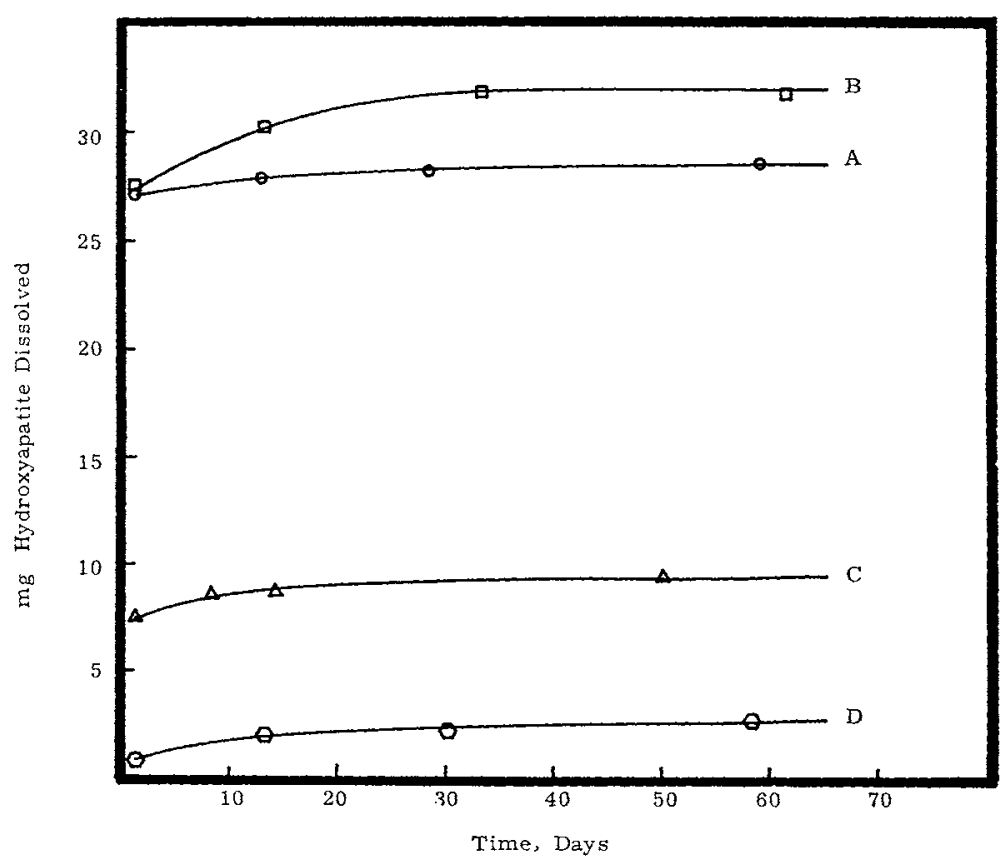




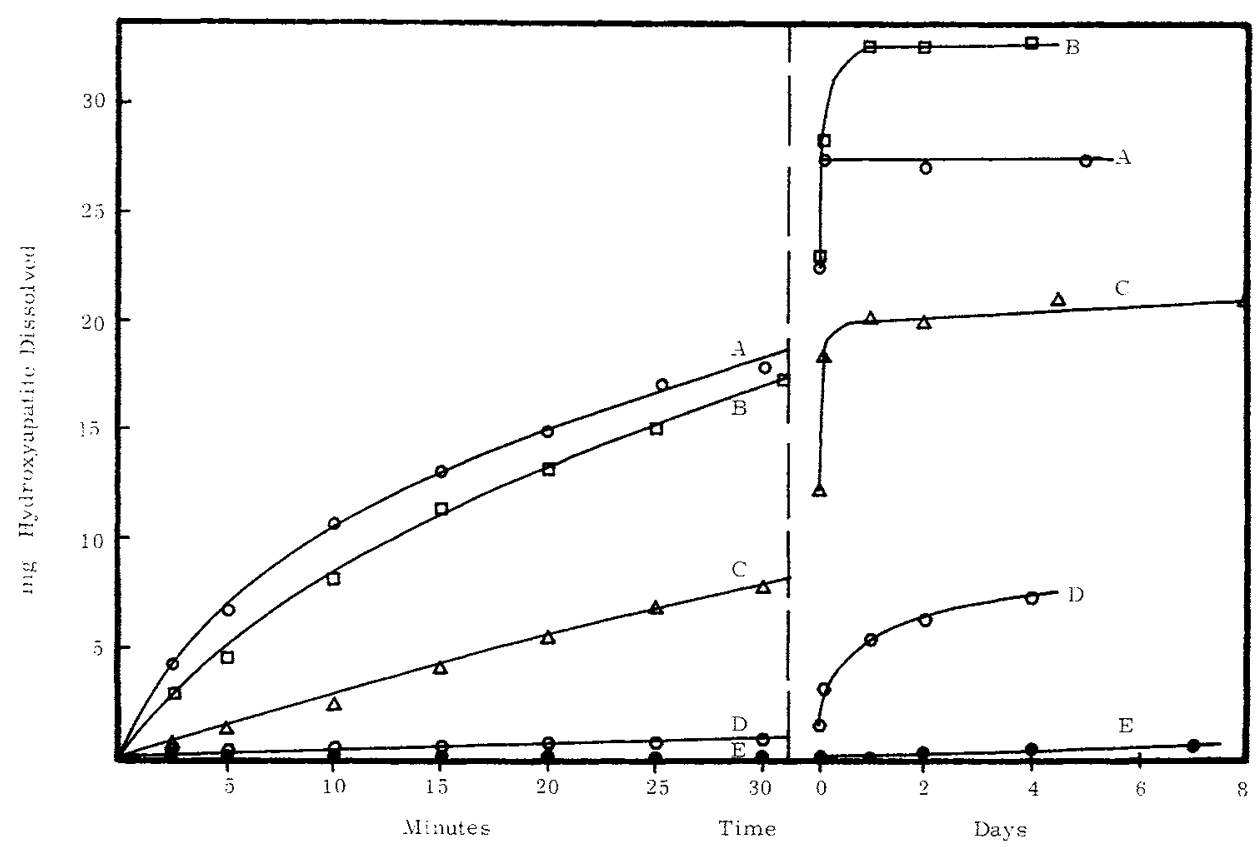

A, O, Control; B, $\square, 0.1 \mathrm{mM} ; \mathrm{C}, \triangle, 0.2 \mathrm{mM} D \mathrm{DO}, 0.3 \mathrm{mM} ; \mathrm{E}, \mathrm{O}, 0.4 \mathrm{mM}$.

FIG 6, 6a-Dissolution profiles of preadsorbed TVA apatite in various tetradecylammonium chloride solutions in $\mathrm{pH} 4.5,0.05 \mathrm{M}$ acetate buffer.

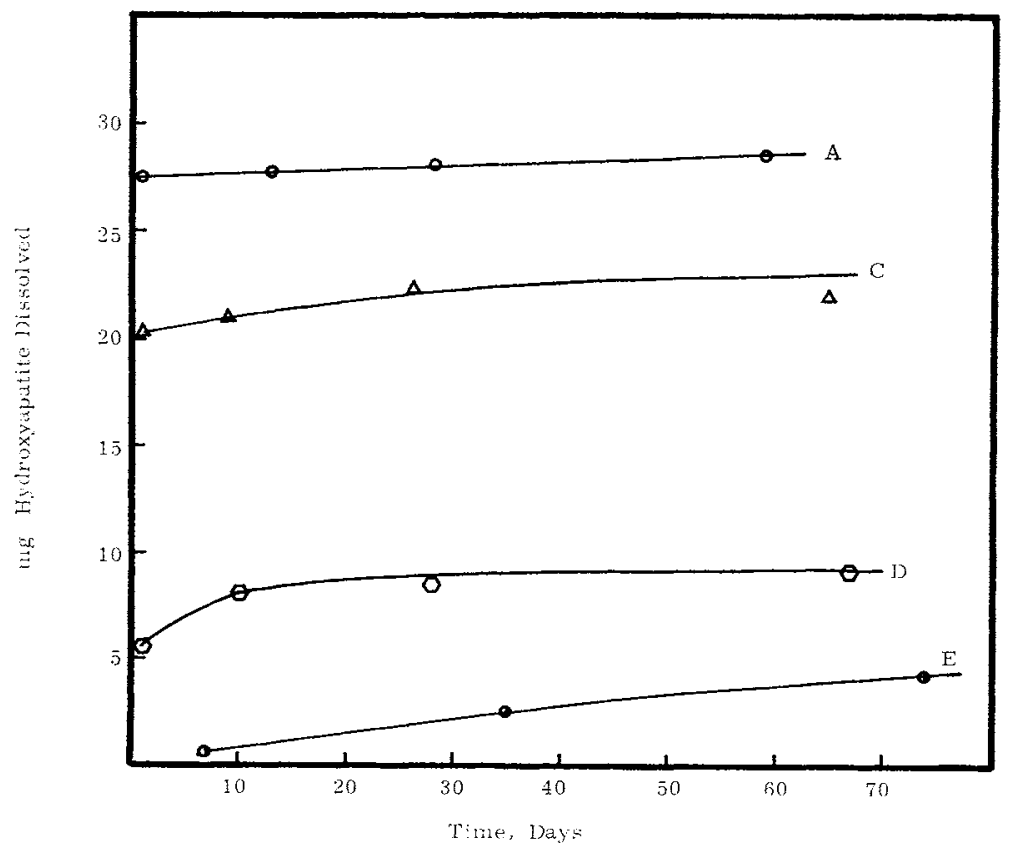




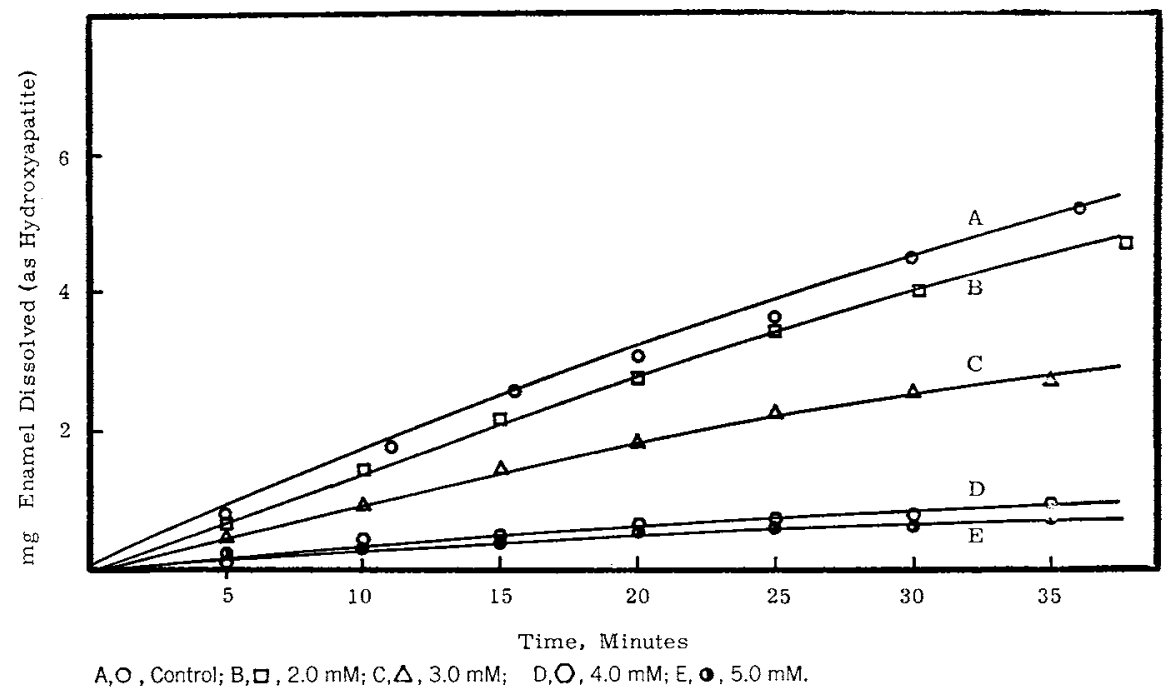

FIG 7.-Dissolution profiles of preadsorbed enamel in various dodecylammonium chloride solutions in $\mathrm{pH} 4.5,0.05 \mathrm{M}$ acetate buffer.

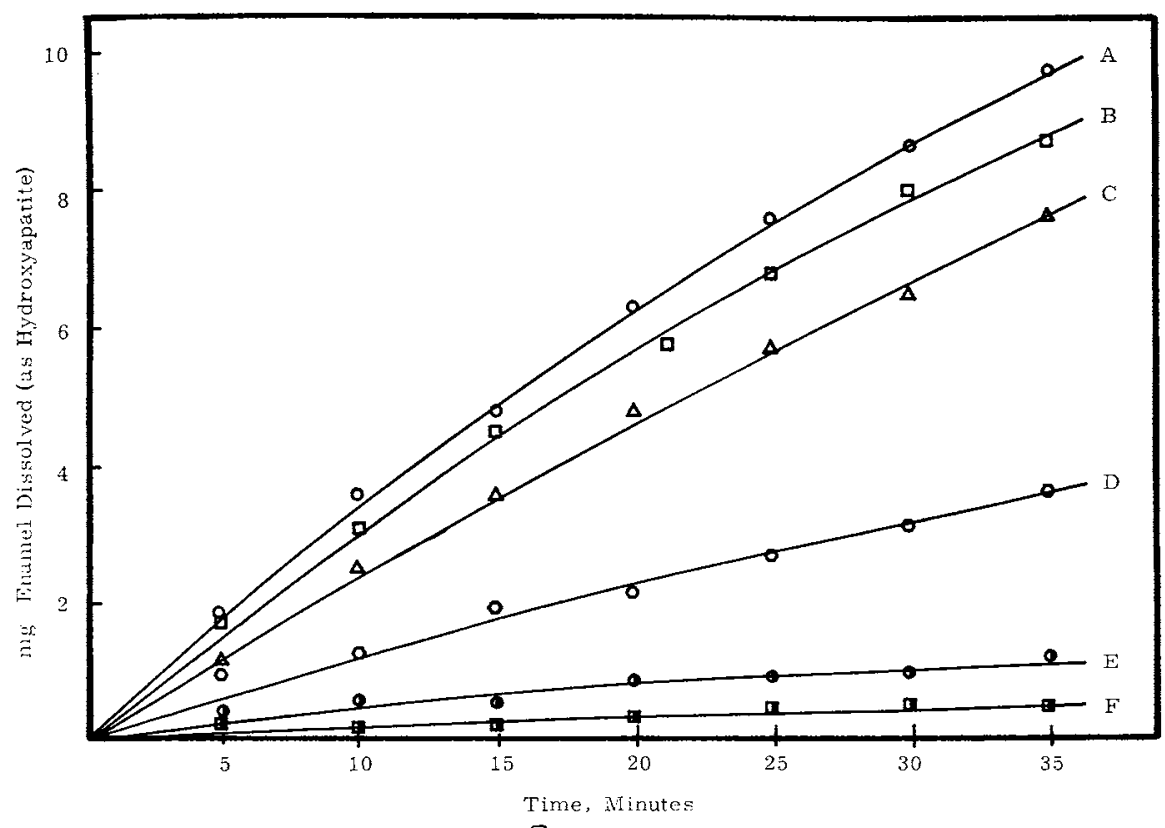

$\mathrm{A}, \bigcirc$, Control; $\mathrm{B}, \square, 0.1 \mathrm{mM} ; \mathrm{C}, \triangle, 0.2 \mathrm{mM} ; \mathrm{D}, \mathrm{O}, 0.3 \mathrm{mM} ; \mathrm{E}, \mathbf{0}, 0.4 \mathrm{mM} ; F, \mathbf{0}, 0.5 \mathrm{mM}$.

FIG 8.-Dissolution profiles of preadsorbed enamel in various tetradecylammonium chloride solutions in $\mathrm{pH} 4.5,0.05 \mathrm{M}$ acetate buffer. 
tardations with either apatite or enamel.

Figures 5 through 8 are representative of typical TVA apatite and enamel dissolution profiles in the presence of various surfactant concentrations in $\mathrm{pH} 4.5$ and $0.05 \mathrm{M}$ acetate buffer. In a control experiment, the exact experimental conditions, including preadsorption, were maintained except that no surfactant was present. In all cases, the apatite dissolved congruently. Although the molybdate reagent in the phosphate assay interacted with the higher surfactant concentrations, the assay was not significantly altered.

For means of comparison, the retardation factors for both the TVA apatite and the enamel rate runs were calculated by taking the ratios of the times necessary to attain the same amount of dissolution in the surfactant experiment as in the control run. The retardation factor was then averaged over a particular interval. Figure 9 shows the retardation factor as a function of the different surfactant concentrations. Results from the enamel study demonstrated a similar type of rate retardation dependence on surfactant concentrations.

The correlation of adsorption data with rate retardation data for DAC can be seen by referring to Figures 3 (Curve $A$ ) and 9 (Curve $B$ ). No rate retardations were observed until appreciable adsorption took place, and then the retardations were found to increase with increasing adsorption.

When the effect of CPC on the dissolution of apatite was explored at two concentrations $(0.08$ and $2.0 \mathrm{mM})$, one concentration above and one below the measured $C M C$ of $0.12 \mathrm{mM}$, no significant rate reductions were observed. The estimated ionic strength for these runs was approximately 0.02 . This was sufficiently high so that the adsorption of CPC was expected to be very low (Fig 4). Similar results were obtained in the enamel dissolution studies, where the presence of CPC at 1 or $10 \mathrm{~m} M$ concentration showed no retardation.

Dissolution experiments with TVA apatite were also performed in $\mathrm{pH} 5.0$ and 0.05 $M$ acetate buffer in selected surfactant solutions. Figure 10 is an example of apatite dissolution in the presence of tetradecylammonium chloride (TAC) at $\mathrm{pH}$ 5.0. At this $\mathrm{pH}$, plots of the retardation factor versus surfactant concentration were displaced by about $35 \%$ to lower concentrations of
TAC when compared to the retardation results in pH 4.5, $0.05 M$ acetate buffer. A similar shift of about $50 \%$ was observed when $0.1 M$ sodium chloride was added to the dissolution media ( $\mathrm{pH} 4.5$ ).

\section{Discussion}

ADSORPTION BEHAVIOR.-The $S$-shaped nature of the adsorption isotherms illustrates nonideal behavior when compared to the Langmuir model ${ }^{12}$ for adsorption. It suggests a cooperative mechanism for adsorption involving lateral interactions of the hydrocarbon portion of the molecules. ${ }^{13}$ Also, the possibility for more than one monomolecular layer cannot be completely disregarded in the case of DAC. Using the value of $66.1 \mathrm{M}^{2} / \mathrm{gm}$ (Table 1) for the surface area of Victor hydroxyapatite, a complete monomolecular layer would require the adsorption of 0.54 millimoles of the dodecylammonium ion. This assumes an area of $20.5 \mathrm{~A}^{2}$ per molecule which is the reported value for condensed films of long-chain amines. ${ }^{14}$ The experimental value for the maximum amount adsorbed from water was 0.64 millimoles/gm. Although this is in fair agreement for a monolayer, a somewhat larger area per molecule or a smaller effective apatite surface area (due to solvent adsorption or to the ability of a gas molecule to penetrate areas during gas adsorption that are inaccessible to the larger organic molecule during adsorption from solution) would suggest bilayer adsorption.

The CPC plateau value in water reached only $16 \%$ of the DAC plateau value. If CPC and DAC were oriented similarly at the solid surface, the difference in the plateau values could indicate that the pyridinium-head group does not allow close packing at the interface and therefore gives poorer adsorption. It is possible that the nature of the pyridinium group may not interfere with the interactions of the aliphatic tails in a micelle, but prevents good interactions at a planar surface.

The addition of sodium chloride to the adsorption media altered the adsorption process differently for DAC and CPC. Such behavior may be rationalized in terms of the effects of salt on the critical micelle concentration and the apatite adsorption affinity for the two surfactants. ${ }^{15}$

DisSOlution RATE RETARDATION.-In this discussion, the adsorbed surfactants at the 


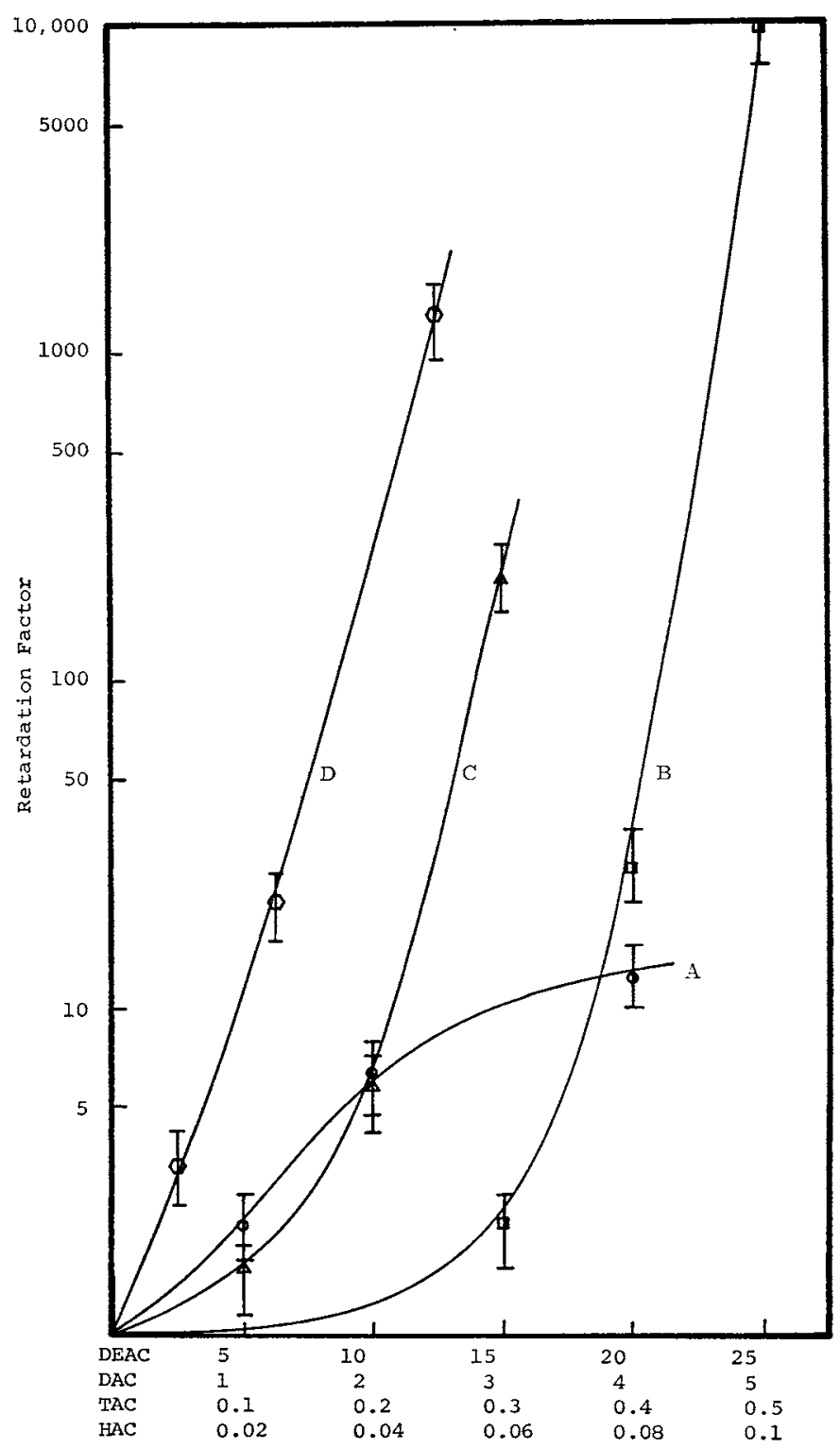

$A, O, D E A C ; B, D, D A C ; C, \triangle, T A C ; D, O, H A C$.

FIG 9.-Retardation profiles of TVA apatite as a function of surfactant concentrations in pH 4.5, $0.05 M$ acetate buffer.

enamel-liquid or hydroxyapatite-liquid interface are considered to form a molecular film. Therefore, in order for a dissolved ion to reach the bulk solution, it must pass through the interfacial film and the diffusion layer regions. ${ }^{16}$ The results of this investigation suggest that the rate determining step is controlled by this film.

Figure 11 shows a plot of the logarithm of the surfactant concentration at equal retardations versus carbon chain length of the ammonium ions. This linear relationship corresponds to about a threefold increase in rate retardation per increase in carbon num- 


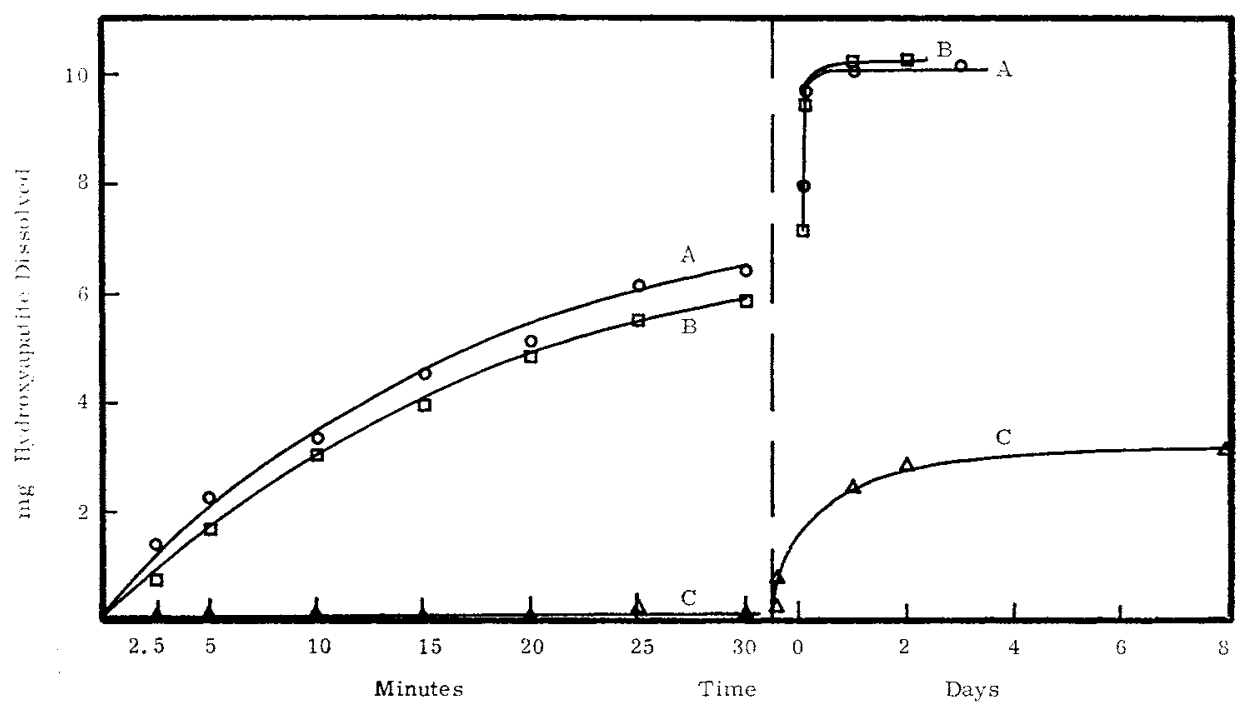

$A, O$, Control; $B, D, 0.1 \mathrm{mM} ; C, \triangle, 0.2 \mathrm{mM}$.

FIG 10.-Dissolution profiles of preadsorbed TVA apatite in various tetradecylammonium chloride solutions in $\mathrm{pH} 5.0,0.05 \mathrm{M}$ acetate buffer.

ber, and it is analogous to Traube's rule. ${ }^{1:}$ This relationship reflects the greater adsorbing tendency (binding strength) of the higher homologues due to the greater number of methylene groups. Ionic transport, therefore, may take place through an all-ornone process across the film, the probability of which depends on the monolayer state and composition. This single step process can be accounted for by the fluctuation desorption of a surfactant molecule at a site of dissolution. A similar mechanism has been used to explain the retardation of water evaporation rates by condensed monolayers. ${ }^{18}$ A similar example of the correlation between adsorption and rate retardation was found when dissolution and DAC adsorption experiments were conducted with and without $0.10 \mathrm{M}$ sodium chloride at $\mathrm{pH}$ 4.5. The observed greater retardations in the presence of sodium chloride may be attributed to the greater surfactant adsorbing tendency at the higher ionic strength. The greater rate retardation in $\mathrm{pH} 5.0$ buffer may also be attributed to the same tendency because of a somewhat greater ionic strength at the higher $\mathrm{pH}$ value.

It should be pointed out that the long time dissolution data (Fig 5a, 6a) in the presence of the long-chain ammonium chlorides do not rule out the possibility of a solubility change of hydroxyapatite. Such changes would, however, be of a much smaller order of magnitude than the kinetic effects of the surfactant. In view of the complex solubility behavior of apatite itself, it is not surprising that the adsorption of these surfactants may influence the apparent solubility. Studies are under way to demonstrate the self-consistent interrelationships of both the kinetic and the apparent thermodynamic changes brought about by these adsorbing agents.

\section{Conclusions}

The influence of two types of cationic surfactants on the dissolution rates of enamel and hydroxyapatite was investigated. Surfactant adsorption onto hydroxyapatite showed that environmental conditions can significantly alter the adsorption process and concomitantly affect dissolution rates. Ionic strength, surfactant type, and micelle formation all played important roles in the adsorption process. Under the experimental dissolution conditions ( $\mathrm{pH} 4.5)$, the adsorption of CPC was low and did not modify the dissolution rate of hydroxyapatite or enamel. On the other hand, the adsorption of dodecylammonium chloride onto apatite was measured, and significant rate reductions were observed with it and with the three other members of the homologous series. The greater retardation efficiency 


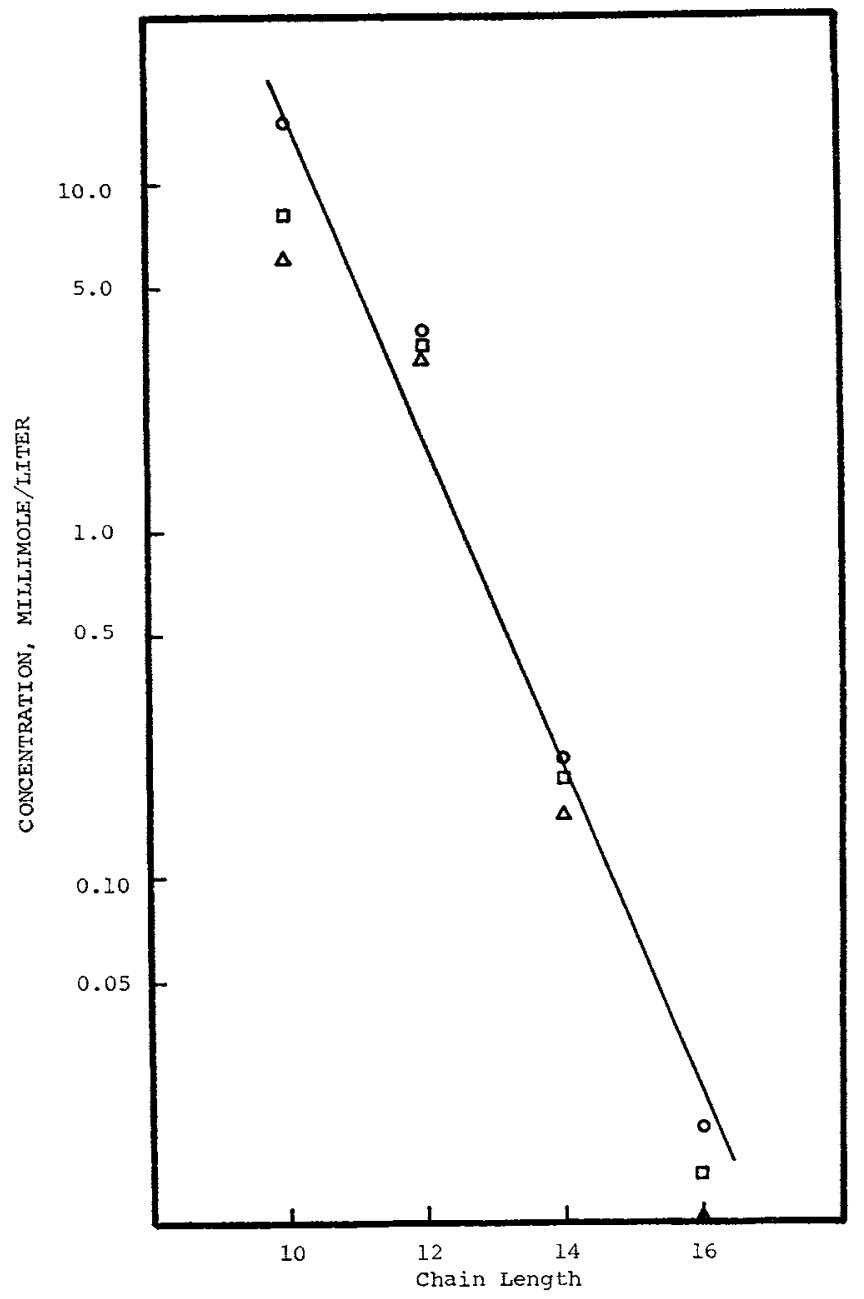

Key: $\Delta, 2.5$ retardation factor; $\square, 5 ; 0,10$.

FIG 11.-Surfactant concentrations at equal dissolution retardations (in $\mathrm{pH} 4.5,0.05 M$ acetate buffer) as a function of carbon chain length. Line drawn is based on a retardation factor of 10 .

per increased chain length was found to obey Traube's rule. The greater rate reduction with equivalent concentrations of DAC in the presence of sodium chloride was attributed to its greater adsorbing tendency. Hydroxyapatite dissolution results were in good agreement with the results of enamel dissolution experiments, and it was expected that the same factors would be operating in both systems.

It was proposed that the fluctuation de- sorption of a surfactant molecule provides a reasonable explanation for the rate determining process in the retardation of dissolution rates by long-chain ammonium chlorides.

\section{References}

1. Meckel, A.H.: The Formation and Properties of Organic Films on Teeth, Arch Oral Biol 10:585-597, 1965.

2. Manly, R.S., and Manly, K.F.: Influence 
of Cephalin on Solution Rate of Tooth Enamel, J Dent Res 42:565-567, 1963.

3. MYERS, H.M.: Effect of Alizarin on Calcium Release from Apatite, $J$ Dent Res 42: $1547,1963$.

4. Green, R.W., and Walsh, J.P.: The Protection of the Wet Enamel Surface by Adsorbed Films, $J$ Dent Res 30:218-224, 1951.

5. IRWIN, M.; LEAVER, A.G.; and WALSH, J.P.: Further Studies on the Influence of Surface Active Agents on Decalcification of the Enamel Surface, J Dent Res 36:166$172,1957$.

6. TONZETICh, J.; Bouchal, A.W.; KING, W.J.; and Richter, V.J.: The Effect of Temperature on Powdered Enamel Solubility Reduction by Sodium N-Palmitoyl Sarcosinate, Alabama J Med Sci 1:268-271, 1964.

7. Pearce, E.I.F., and BibBy, B.G.: Protein Adsorption on Bovine Enamel, Arch Oral Biol 11:329-336, 1966.

8. Pearce, E.I.F., and BibBy, B.G.: Effects of Time, Surface Area, $\mathrm{pH}$, and Some Ions on Protein Adsorption, Arch Oral Biol 11:825-832, 1966.

9. Grenby, T.H.: Phytates in Decalcification Tests In Vitro, Arch Oral Biol 12:531-537, 1967.

10. Ino, T.; Kondo, T.; Meguro, K.; and YODA, I.: Interaction between Fluorescence
Indicators and Surface Active Agents, Bull Chem Soc Japan 76:220-222, 1955.

11. Gee, A.; Domingues, L.P.; and Deitz, V.R.: Determination of Inorganic Constituents in Sucrose Solutions, Anal Chem 26: 1487-1491, 1954.

12. LANGMUIR, I.: The Adsorption of Gases on Plane Surfaces of Glass, Mica, and Platinum, $J$ Amer Chem Soc 40:1361-1402, 1918.

13. West, W.; Carroll, B.H.; and Whitcomb, D.H.: The Adsorption of Sensitizing Dyes in Photographic Emulsions, $J$ Phys Chem 56:1054-1067, 1952

14. ADAM, N.K.: The Physics and Chemistry of Surfaces, London: Oxford University Press, 1941, p 51.

15. Roseman, T.J.: The Mechanism of Action of Interfacially Adsorbed Agents on the Demineralization Rate of Enamel: PhD Thesis, The University of Michigan, 1967.

16. HiguchI, W.I.; Gray, J.A.; HefFerRen, J.J.; and PATEL, P.R.: Mechanisms of Enamel Dissolution in Acid Buffers, $J$ Dent Res 44:330-341, 1965.

17. Traube, J.: Uber die Capillaritätsconstanten Organischer Stoffe in Wässerigen Lösungen, Leibigs Ann 265:27-55, 1891.

18. LAMER, V.K.: Retardation of Evaporation by Monolayers, New York: Academic Press, 1962, pp 9-33 and 59-66. 